\title{
ANALISIS DEKOMPOSISI WAVELET PADA PENGENALAN POLA LURIK DENGAN METODE LEARNING VECTOR QUANTIZATION
}

\author{
Bambang Robi'in \\ eure_bbg@yahoo.com \\ Akademi Teknik PIRI Yogyakarta
}

\begin{abstract}
Abstrak
Indonesia merupakan negara yang terdiri dari banyak suku dan adat istiadat. Keragaman budaya di Indonesia juga dapat dilihat dari kerajinan tenun seperti songket dari daerah sumatra, ulos dari daerah batak, dan kain lurik dari daerah jawa tengah. Kain lurik dibuat dengan motif bergaris-garis atau kotak-kotak tetapi memiliki pola yang bermacam-macam dan sulit dibedakan antara satu pola dengan yang lainnya. Dalam penelitian ini, pengenalan pola dilakukan dengan membangun jaringan syaraf tiruan dengan metode Learning Vector Quantization (LVQ). Proses dekomposisi yang digunakan untuk ekstraksi ciri suatu citra ini digunakan metode Discrete Wavelet Transform (DWT). Hasil penelitian menunjukan bahwa Jaringan syaraf tiruan untuk Pengenalan pola menggunakan metode LVQ dan wavelet haar, wavelet daubechies, wavelet symlet, dan wavelet coiflet menghasilkan sebuah jaringan syaraf tiruan yang memiliki kinerja berbeda-beda. Hasil terbaik dari kinerja jaringan ini diperoleh kinerja terbaik dengan akurasi sebesar $80 \%$ pada JST yang menggunakan metode dekomposisi wavelet haar.
\end{abstract}

Kata kunci: Citra, Lurik, Jaringan syaraf tiruan, Learning Vector Quantization, Wavelet

\section{Pendahuluan}

Indonesia merupakan negara yang terdiri dari banyak suku dan adat istiadat. Masing-masing daerah di Indonesia memiliki budaya yang berbeda-beda antara daerah yang satu dengan yang lainnya. Keragaman budaya di Indonesia juga dapat dilihat dari kerajinan tenun yang ada di Indonesia seperti songket dari daerah sumatra, ulos dari daerah batak, dan kain lurik dari daerah jawa tengah.

Lurik merupakan tekstil tradisional yang pernah berkembang di beberapa daerah di Indonesia seperti di daerah Yogyakarta, Surakarta, dan sekitarnya. Lurik berasal dari bahasa jawa yaitu kata lorek yang berarti garis-garis atau dari kata lirik-lirik yang berarti bergaris-garis tetapi garisnya kecilkecil [1]. Lurik berasal dari daerah jawa tengah yang merupakan kain hasil tenun dengan berbahan benang. Motif dasar dari lurik ini berbentuk garis-garis atau kotak-kotak dengan warna suram yang pada umumnya diselingi dengan warna benang.

Kain lurik merupakan tekstil tradisional yang terus berkembang sampai saat ini. Kain lurik kini hadir dalam berbagai bentuk seperti selendang, surjan, bahkan baju modern yang dibuat dengan bahan lurik. Walaupun kain lurik ini dibuat dengan motif bergaris-garis atau kotak-kotak, tetapi kain lurik ini hadir dengan berbagai bentuk pola/motif yang bermacam-macam. Masing-masing pola pada kain lurik memiliki ciri masing-masing. Sifat dari motif kain lurik yang berbentuk garis-garis atau kotakkotak kadang membuta bingung orang awam. Sulit membedakan antara motif yang satu dengan yang lainnya jika seseorang tidak memiliki pemahaman tentang kain lurik dengan baik.

Perkembangan teknologi informasi yang kian pesat sekarang ini memberikan dampak yang positif bagi hampir seluruh aspek kehidupan. Banyak aplikasi cerdas dikembangkan untuk membantu manusia dalam menyelesaikan persoalan hidupnya. Salah satu aplikasi yang banyak dikembangkan adalah aplikasi pengenalan pola. Aplikasi sistem serdas pengenalan pola ini digunakan untuk mengenali pola pada suatu citra digital dengan terlebih dahulu mendapatkan pelatihan. Salah satu metode yang dapat digunakan dalam pengenalan pola ini adalah Learning Vector Quantization.

Learning Vector Quantization merupakan jaringan syaraf dengan tipe arsitektur jaringan lapis tunggal umpan-maju (Single Layer Feedforward) [2]. Learning Vector Quantization merupakan salah satu metode untuk melakukan pembelajaran pada lapisan kompetitif yang terawasi. Lapisan kompotetitif akan secara otomatis belajar untuk mengklasifikasikan vektor-vektor input. Kelas-kelas yang kemudian didapatkan dari lapisan kompetitif ini sepenuhnya bergantung pada jarak antara vektor-vektor input. Jika terdapat vektor input yang mendekati sama, maka lapisan kompetitif akan meletakkan kedua vektor tersebut dalam kelas yang sama.

Dalam proses pengenalan pola, terutama dalam pengenalan pola pada suatu citra juga banyak digunakan suatu metode yang dapat digunakan untuk melakukan ekstraksi ciri. Metode ekstraksi ciri dari suatu citra ini disebut dengan dekomposisi. Banyak metode yang dapat digunakan dalam proses dekomposisi ini, salah satunya adalah metode wavelet. Transformasi merupakan proses pengubahan 
data atau sinyal ke dalam bentuk lain agar lebih mudah dianalisis [3]. Transformasi wavelet atau dikenal dengan Discrete Wavelet Transform (DWT) merupakan metode yang digunakan dalam pengolahan citra digital. Proses transformasi wavelet secara konsep dillakukan dengan membagi (dekomposisi) citra menjadi empat ian sub image. Setiap sub image berukuran seperempat dari citra asli. Discrete Wavelet Transform (DWT) memiliki beberapa jenis diantaranya adalah wavelet Haar, wavelet symlet, wavelet coiflet, wavelet daubechies, dan lain sebagainya.

Fokus dalam penelitian ini adalah bagaimana melakukan pengenalan pola untuk citra lurik berdasarkan motif dari kain lurik. Sistem pengenalan pola menggunakan jaringan syaraf dengan metode Learning Vector Quantization (LVQ). Ekstraksi citra digital kain lurik menggunakan metode Discrete Wavelet Transform (DWT). Jenis wavelet yang digunakan dalam adalah wavelet Haar, wavelet symlet, wavelet coiflet, dan wavelet daubechies. Tujuan dari penelitian ini adalah mengetahui bagaimana jaringan syaraf tiruan dengan LVQ dan Wavelet digunakan untuk mengenali pola kain lurik. Melakukan analisa terhadap unjuk kerja beberapa jenis wavelet sebagai metode dekomposisi dalam pengenalan pola motif kain lurik menggunakan metode LVQ.

\section{Metode}

Jaringan syaraf tiruan (JST) dalam pengenalan pola citra kain lurik menggunakan metode LVQ (Learning Vector Quantization) dan wavelet dalam melakukan dekomposisi citra. Tahapan dalam proses pengenalan pola tersebut terlihat pada gambar 1 di bawah ini.

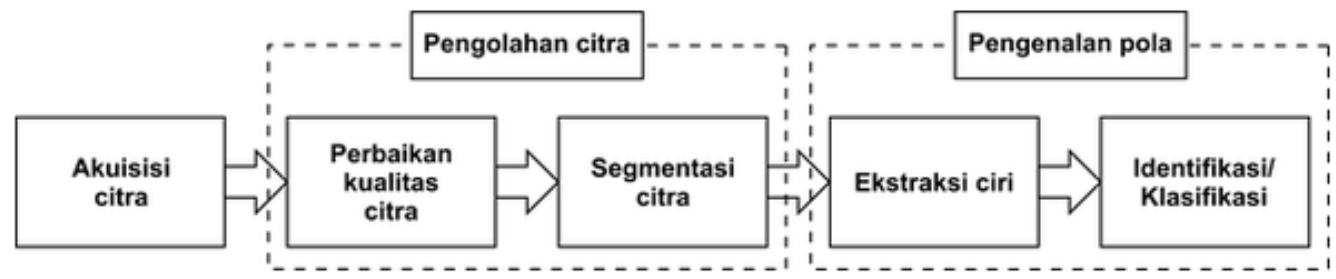

Gambar 1. Tahapan Penelitian

Pada tahap awal adalah proses akuisisi citra dimana terdapat sejumlah $\mathrm{n}$ image sebagai data masukan. Tahap berikutnya dalah proses pengolahan citra. Proses ini dilakukan untuk memperbaiki kualitas citra dan segmentasi citra. Salah satu teknik yang dapat dilakukan pada tahap ini adalah tresholding. Tahap berikutnya adalah tahap pengenalan pola. Tahap ini terdiri dari ekstraksi ciri dan identifikasi/klasifikasi pola. Tahap ekstraksi citi dilakukan dengan metode Discrete Wavelet Transform (DWT) dengan pilihan empat jenis wavelet yaitu wavelet haar, wavelet coiflet, wavelet symflet, dan wavelet daubechies. Untuk tahap identifikasi/klasifikasi dilakukan dangan jaringan syaraf tiruan dengan metode Learning Vector Quantization (LVQ).

\subsection{Learning Vector Quabtization (LVQ)}

Learning Vector Quantization merupakan jaringan syaraf dengan tipe arsitektur jaringan lapis tunggal umpan-maju (Single Layer Feedforward) [2]. Learning Vector Quantization merupakan salah satu metode untuk melakukan pembelajaran pada lapisan kompetitif yang terawasi [4]. Lapisan kompotetitif akan secara otomatis belajar untuk mengklasifikasikan vektor-vektor input. Kelas-kelas yang kemudian didapatkan dari lapisan kompetitif ini sepenuhnya bergantung pada jarak antara vektor-vektor input. Jika terdapat vektor input yang mendekati sama, maka lapisan kompetitif akan meletakkan kedua vektor tersebut dalam kelas yang sama. Arsitektur dari jaringan Learning Vector Quantization adalah seperti pada gambar 2 berikut ini. 


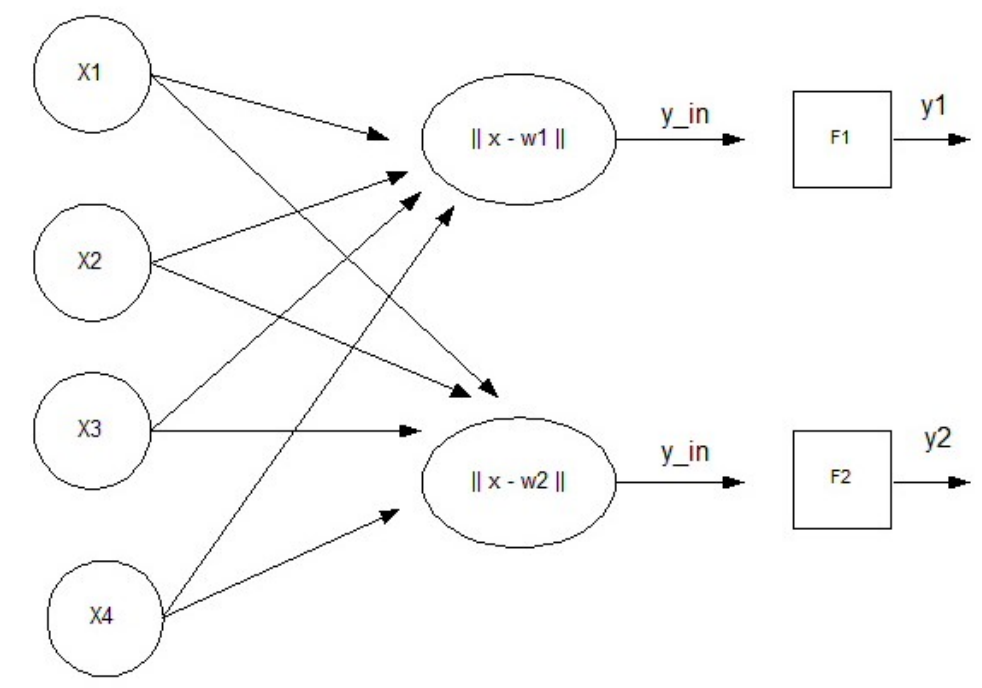

Gambar 2. Arsitektur LVQ

Algoritma Learning Vector Quantization adalah terdiri dari beberapa langkah berikut ini:

Langkah $0 \quad$ : Inisialiasi vektor referensi dan laju pembelajaran (Learning rate) : $\alpha$

Langkah 1 : selama kondisi berhenti bernilai salah maka kerjakan langkan 2 dan 3 . Kondisi berhenti akan bernilai benar jika perulangan mencapai nilai perulangan maksimal dan perubahan rasio lebih kecil dari minimal error).

Langkah 2 : 'untuk masing-masing vektor pelatihan, kerjakan :

a. Tentukan j sehingga $\| \mathrm{x}-$ wj $\|$ bernilai minimum dengan menggunakan rumus pada persamaan (1).

$$
C j=\sqrt{\sum_{i=1}^{n}\left(X i-W_{i j}\right)^{2}}
$$

b. Perbaiki Wj dengan:

i. Jika $\mathrm{T}=\mathrm{Cj}$ maka

Wj(baru $)=W j($ lama $)+\alpha[X-W j($ lama $)]$

ii. Jika $T \neq C$ j maka

Wj (baru) $=$ Wj (lama) $-\alpha[X-W j($ lama $)]$

Langkah 3 : Kurangi laju pembelajaran (learning rate)

$\alpha=\alpha^{*}$ pengurang rasio

Langkah 4 : Tes kondisi berhenti

Keterangan:

$\mathrm{T}$ : Target

W : Bobot

$\mathrm{J}$ : Jumlah selisih data dan botot

$\alpha$ : Laju pembelajaran

$\mathrm{C}:$ Kelas selisih bobot

$\mathrm{x}$ : data

\subsection{Transformasi Wavelet Diskrit}

Transformasi wavelet diskrit digunakan untuk melakukan dekomposisi citra digital. Prinsip dasar dari transformasi ini adalah mendapatkan representasi waktu dan skala dari sebuah sinyal dengan menggunakan teknik pemfilteran digital dan operasi. Sinyal pada awalnya dilewatkan pada rangkaian filter high pass dan low pass, kemudian setengah dari masing-masing keluaran diambil sebagai contoh melalui sub sampling [5] [6]. Proses ini merupakan proses dekomposisi satu tingkat. Keluaran dari filter low pass digunakan untuk masukan pada proses tingkat berikutnya. Perhitungan untuk low pass filter menggunakan persamaan (2) dan perhitungan high pass filter menggunakan persamaan (3) sebagai berikut: 


$$
\begin{aligned}
& \text { Ylow }[n]=\sum_{k=-\infty}^{\infty} X[k] g[2 n-k] \\
& \text { Yhigh }[n]=\sum_{k=-\infty}^{\infty} X[k] h[2 n-k]
\end{aligned}
$$

Dalam penelitian ini digunakan empat jenis transformasi wavelet yaitu wavelet haar, wavelet symlet, wavelet coiflet, dan wavelet daubechies. Tingkat dekomposisi wavelet yang digunakan dalam penelitian ini adalah 4 level.

\section{Hasil dan Pembahasan}

\subsection{Data Citra}

Data citra yang digunakan dalam penelitian ini adalah data citra motif lurik. Citra ini berukuran 512 x 512. Tabel 1 berikut ini adalah data citra motif lurik,

Tabel 1. Data Citra Lurik

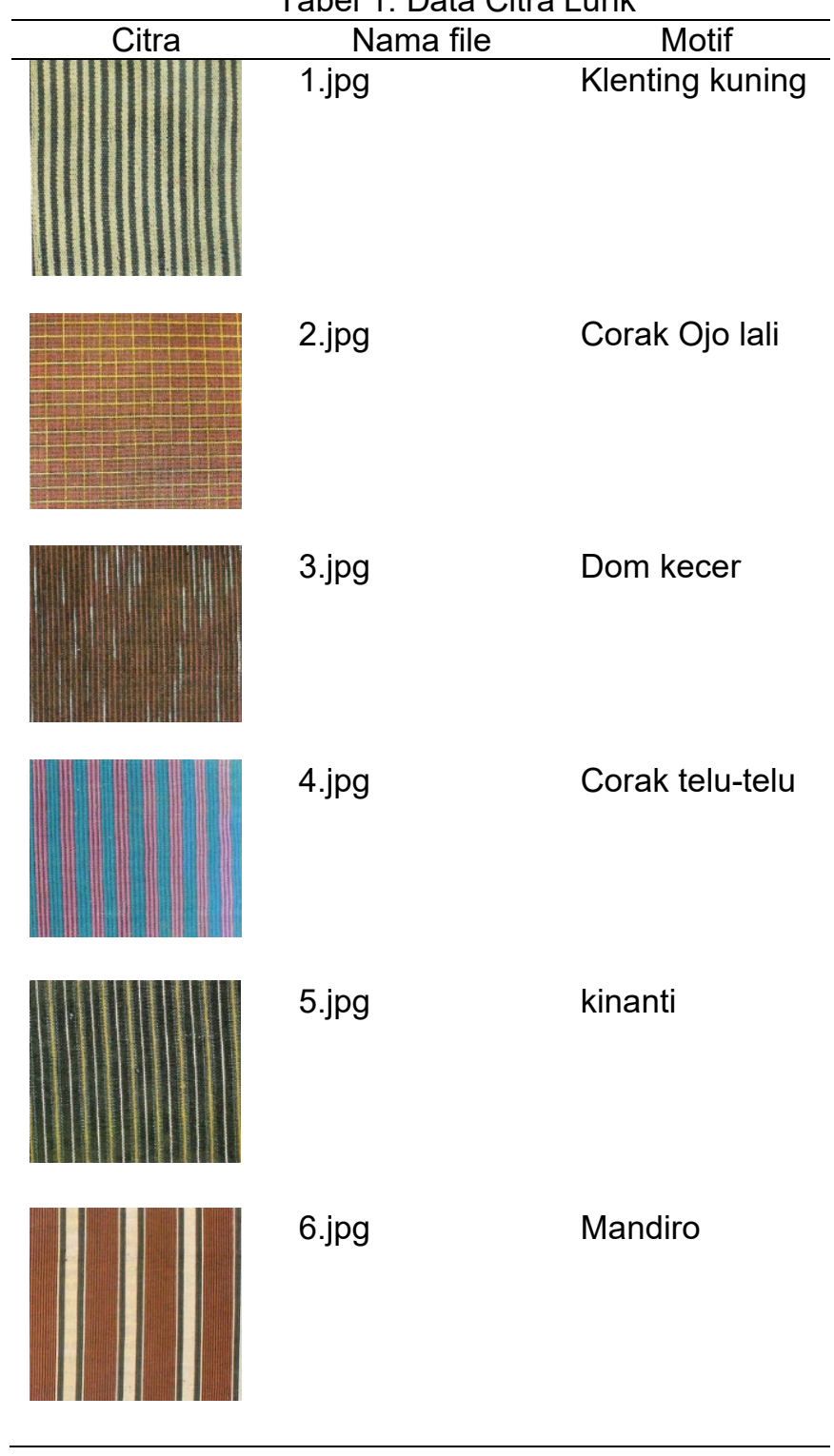


ILKOM Jurnal Ilmiah Volume 9 Nomor 2 Agustus 2017

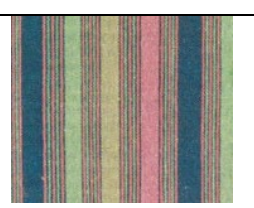

7.jpg

Megiren

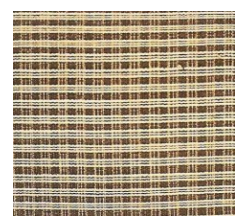

8.jpg

Tumenggungan

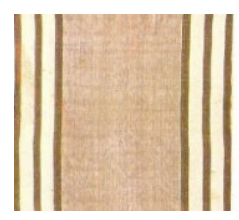

9.jpg

Dengklung

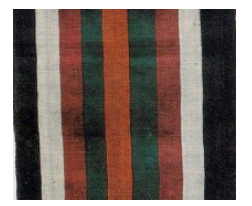

10.jpg

Kluwung

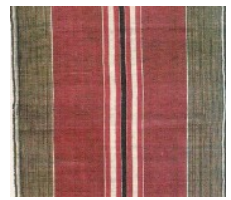

11.jpg

Sulur ringin

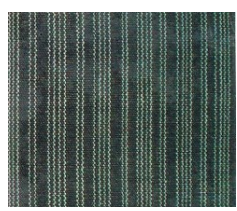

12.jpg

Loro-pat

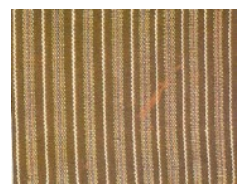

13.jpg

Kembang

bayem

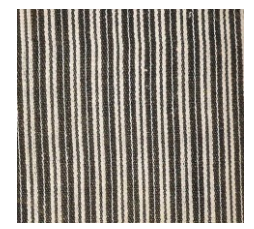

14.jpg

Bribil

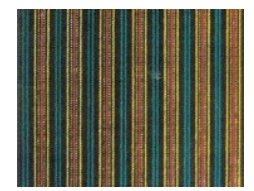

15.jpg

Sapit urang

Udan liris

16.jpg 


\subsection{Ekstraksi Citra}

Proses ekstraksi citra terjadi ketika citra akan dijadikan sebagai data training dan data pengujian. Data citra yang awalnya berbentuk matrix akan dilakukan ekstraksi kemudian disimpan dalam bentuk vektor. Metode yang digunakan dalam ekstraksi citra ini adalah metode wavelet dengan level dekomposisi 4 level. Banyaknya metode wavelet yang ada, maka dalam penelitian ini digunakan empat metode wavelet yang berbeda yaitu wavelet haar, wavelet daubechies, wavelet symlet, dan wavelet coiflet.

\section{a. Wavelet Haar}

Metode untuk ekstraksi citra yang digunakan adalah wavelet haar dengan dekomposisi level 4. Citra yang semula berukuran 512 X 512 pixel akan berubah menjadi $32 \times 32$ pixel. Hasil ekstraksi ini kemudian akan di transformasikan dalam bentuk vektor dengan ukuran 1024. Vektor hasil ekstraksi citra ini yang akan digunakan sebagai vektor input.

\section{b. Wavelet Daubechies}

Metode untuk ekstraksi citra yang digunakan adalah wavelet daubechies dengan dekomposisi level 4. Citra yang semula berukuran $512 \times 512$ pixel akan berubah menjadi $34 \times 34$ pixel. Hasil ekstraksi ini kemudian akan di transformasikan dalam bentuk vektor dengan ukuran 1156 . Vektor hasil ekatraksi citra ini yang akan digunakan sebagai vektor input.

\section{c. Wavelet Symlet}

Metode untuk ekstraksi citra yang digunakan adalah wavelet symlet dengan dekomposisi level 4. Citra yang semula berukuran 512 X 512 pixel akan berubah menjadi $34 \times 34$ pixel. Hasil ekstraksi ini kemudian akan di transformasikan dalam bentuk vektor dengan ukuran 1156. Vektor hasil ekatraksi citra ini yang akan digunakan sebagai vektor input.

d. Wavelet Coiflet

Metode untuk ekstraksi citra yang digunakan adalah wavelet coiflet dengan dekomposisi level 4. Citra yang semula berukuran 512 X 512 pixel akan berudah menjadi 36 X 36 pixel. Hasil ekstraksi ini kemudian akan di transformasikan dalam bentuk vektor dengan ukuran 1296. Vektor hasil ekatraksi citra ini yang akan digunakan sebagai vektor input.

\subsection{Variasi Parameter}

Parameter yang pertama adalah laju pembejalaran (learning rate). Nilai laju pembelajaran yang digunakan dalam penelitian ini adalah $0.1,0.01,0.001$, dan 0.0001 . Parameter yang kedua adalah maksimum epoch. Nilai maksimum epoch yang digunakan dalam penelitian ini terdiri dari 4 nilai yaitu 1000, 2000, 3000, dan 4000.

\subsection{Hasil Pengujian}

Penelitian ini telah dilakukan dengan menguji 16 citra untuk mengetahui kinerja JST yang dibangun dengan menggunakan metode wavelet dan LVQ. Pengujian telah dilakukan dengan variasi metode wavelet, learning rate, dan maksimum epoch yang masing-masing memiliki 4 nilai yang berbeda-beda. Hasil pengujian dapat dilihat pada table 2 berikut ini.

Tabel 2. Hasil Pengujian

\begin{tabular}{lllllll}
\hline No & Jenis Wavelet & Learning Rate & Epoch & Waktu & MSE & Akurasi \\
\hline 1 & Haar & 0.1 & 1000 & $6: 14$ & 0.0254 & $60 \%$ \\
2 & Haar & 0.1 & 2000 & $12: 38$ & 0.0285 & $60 \%$ \\
3 & Haar & 0.1 & 3000 & $18: 3$ & 0.0256 & $68 \%$ \\
4 & Haar & 0.1 & 4000 & $25: 35$ & 0.0286 & $64 \%$ \\
5 & Haar & 0.01 & 1000 & $6: 17$ & 0.0194 & $76 \%$ \\
6 & Haar & 0.01 & 2000 & $12: 34$ & 0.0162 & $80 \%$ \\
7 & Haar & 0.01 & 3000 & $19: 27$ & 0.0192 & $76 \%$ \\
8 & Haar & 0.01 & 4000 & $30: 18$ & 0.0192 & $76 \%$ \\
9 & Haar & 0.001 & 1000 & $7: 27$ & 0.0193 & $76 \%$ \\
10 & Haar & 0.001 & 2000 & $14: 12$ & 0.0194 & $76 \%$ \\
11 & Haar & 0.001 & 3000 & $18: 39$ & 0.0163 & $80 \%$ \\
12 & Haar & 0.001 & 4000 & $26: 42$ & 0.0160 & $80 \%$ \\
13 & Haar & 0.0001 & 1000 & $6: 22$ & 0.0256 & $68 \%$ \\
14 & Haar & 0.0001 & 2000 & $12: 44$ & 0.0256 & $68 \%$ \\
15 & Haar & 0.0001 & 3000 & $21: 04$ & 0.0223 & $72 \%$ \\
16 & Haar & 0.0001 & 4000 & $26: 45$ & 0.0224 & $72 \%$ \\
17 & Daubechies & 0.1 & 1000 & $6: 10$ & 0.0286 & $64 \%$ \\
\hline
\end{tabular}


ILKOM Jurnal Ilmiah Volume 9 Nomor 2 Agustus 2017

\begin{tabular}{|c|c|c|c|c|c|c|}
\hline 18 & Daubechies & 0.1 & 2000 & $13: 31$ & 0.0256 & $60 \%$ \\
\hline 19 & Daubechies & 0.1 & 3000 & $17: 22$ & 0.0288 & $60 \%$ \\
\hline 20 & Daubechies & 0.1 & 4000 & $28: 05$ & 0.0320 & $60 \%$ \\
\hline 21 & Daubechies & 0.01 & 1000 & $6: 27$ & 0.0223 & $72 \%$ \\
\hline 22 & Daubechies & 0.01 & 2000 & 13450 & 0.0192 & $76 \%$ \\
\hline 23 & Daubechies & 0.01 & 3000 & 19:46 & 0.0244 & $72 \%$ \\
\hline 24 & Daubechies & 0.01 & 4000 & 27:08 & 0.0244 & $72 \%$ \\
\hline 25 & Daubechies & 0.001 & 1000 & $7: 34$ & 0.0246 & $72 \%$ \\
\hline 26 & Daubechies & 0.001 & 2000 & 13:02 & 0.0246 & $72 \%$ \\
\hline 27 & Daubechies & 0.001 & 3000 & $20: 33$ & 0.0244 & $72 \%$ \\
\hline 28 & Daubechies & 0.001 & 4000 & $26: 32$ & 0.0244 & $72 \%$ \\
\hline 29 & Daubechies & 0.0001 & 1000 & $06: 27$ & 0.0320 & $60 \%$ \\
\hline 30 & Daubechies & 0.0001 & 2000 & 13:07 & 0.0244 & $64 \%$ \\
\hline 31 & Daubechies & 0.0001 & 3000 & 19:25 & 0.0256 & $68 \%$ \\
\hline 32 & Daubechies & 0.0001 & 4000 & 28:02 & 0.0244 & $72 \%$ \\
\hline 33 & Symlet & 0.1 & 1000 & $7: 25$ & 0.0286 & $64 \%$ \\
\hline 34 & Symlet & 0.1 & 2000 & $15: 31$ & 0.0320 & $60 \%$ \\
\hline 35 & Symlet & 0.1 & 3000 & $24: 23$ & 0.0256 & $64 \%$ \\
\hline 36 & Symlet & 0.1 & 4000 & $26: 15$ & 0.0320 & $60 \%$ \\
\hline 37 & Symlet & 0.01 & 1000 & $7: 35$ & 0.0256 & $68 \%$ \\
\hline 38 & Symlet & 0.01 & 2000 & $15: 12$ & 0.0246 & $72 \%$ \\
\hline 39 & Symlet & 0.01 & 3000 & $24: 20$ & 0.0192 & $76 \%$ \\
\hline 40 & Symlet & 0.01 & 4000 & $26: 34$ & 0.0224 & $72 \%$ \\
\hline 41 & Symlet & 0.001 & 1000 & $7: 27$ & 0.0246 & $72 \%$ \\
\hline 42 & Symlet & 0.001 & 2000 & $15: 27$ & 0.0192 & $76 \%$ \\
\hline 43 & Symlet & 0.001 & 3000 & $25: 04$ & 0.0256 & $68 \%$ \\
\hline 44 & Symlet & 0.001 & 4000 & $27: 23$ & 0.0256 & $68 \%$ \\
\hline 45 & Symlet & 0.0001 & 1000 & $7: 17$ & 0.0286 & $64 \%$ \\
\hline 46 & Symlet & 0.0001 & 2000 & $13: 51$ & 0.0256 & $68 \%$ \\
\hline 47 & Symlet & 0.0001 & 3000 & $18: 46$ & 0.0286 & $64 \%$ \\
\hline 48 & Symlet & 0.0001 & 4000 & 26:01 & 0.0258 & $68 \%$ \\
\hline 49 & Coiflet & 0.1 & 1000 & $8: 10$ & 0.0286 & $64 \%$ \\
\hline 50 & Coiflet & 0.1 & 2000 & $16: 19$ & 0.0286 & $64 \%$ \\
\hline 51 & Coiflet & 0.1 & 3000 & $24: 06$ & 0.0320 & $60 \%$ \\
\hline 52 & Coiflet & 0.1 & 4000 & $32: 02$ & 0.0258 & $64 \%$ \\
\hline 53 & Coiflet & 0.01 & 1000 & $08: 17$ & 0.0226 & $72 \%$ \\
\hline 54 & Coiflet & 0.01 & 2000 & $16: 18$ & 0.0226 & $72 \%$ \\
\hline 55 & Coiflet & 0.01 & 3000 & $24: 21$ & 0.0226 & $72 \%$ \\
\hline 56 & Coiflet & 0.01 & 4000 & $32: 32$ & 0.0258 & $68 \%$ \\
\hline 57 & Coiflet & 0.001 & 1000 & 07:33 & 0.0244 & $72 \%$ \\
\hline 58 & Coiflet & 0.001 & 2000 & $15: 53$ & 0.0246 & $72 \%$ \\
\hline 59 & Coiflet & 0.001 & 3000 & 21:03 & 0.0226 & $72 \%$ \\
\hline 60 & Coiflet & 0.001 & 4000 & 29:06 & 0.0192 & $76 \%$ \\
\hline 61 & Coiflet & 0.0001 & 1000 & 08:19 & 0.0286 & $64 \%$ \\
\hline 62 & Coiflet & 0.0001 & 2000 & $18: 14$ & 0.0286 & $64 \%$ \\
\hline 63 & Coiflet & 0.0001 & 3000 & $21: 14$ & 0.0258 & $68 \%$ \\
\hline 64 & Coiflet & 0.0001 & 4000 & $28: 13$ & 0.0258 & $68 \%$ \\
\hline
\end{tabular}

Dari seluruh pengujian yang telah dilakukan pada penelitian ini, Kinerja JST dengan menggunakan metode wavelet dan LVQ (learning Vector Quantization) dengan akurasi terbaik adalah JST dengan menggunaan metode dekomposisi wavelet haar dengan menghasilkan nilai akurasi tersebesar yaitu $80 \%$.

\section{Kesimpulan dan saran}

Setelah melakukan analisa terhadap apa yang dihasilkan dalam penelitian ini, didapat beberapa kesimpulan mengenai pengenalan pola citra lurik menggunakan metode wavelet dan LVQ (learning vector quantization). Jaringan syaraf tiruan untuk Pengenalan pola menggunakan metode LVQ dan wavelet haar, wavelet daubechies, wavelet symlet, dan wavelet coiflet menghasilkan sebuah jaringan 


\section{ILKOM Jurnal Ilmiah Volume 9 Nomor 2 Agustus 2017}

syaraf tiruan yang memiliki kinerja berbeda-beda. Hasil terbaik dari kinerja jaringan syaraf tiruan yang dibangun dengan LVQ dan metode dekomposisi wavelet haar, wavelet daubechies, wavelet symlet, dan wavelet coiflet diperoleh kinerja terbaik dengan akurasi sebesar $80 \%$ pada JST yang menggunakan metode dekomposisi wavelet haar.

\section{Daftar Pustaka}

[1] S. Wuryani, 2013, "Lurik dan Fungsinya di Masa Lalu," Ornamen, pp. 81-100.

[2] I. Afrianto dan D. Priatama, 2013, "Aplikasi Mobile Pengenalan Citra Menggunakan Metode Learning Vactor Quantization," in Seminar Nasional Teknologi Informasi dan Multimedia 2013 STMIK AMIKOM, Yogyakarta.

[3] Sutarno, 2010, "Analisis Perbandingan Transformasi Wavelet pada Pengenalan Citra Wajah," JURNAL GENERIC, vol. 5, no. 2, pp. 15-21.

[4] G. Kumar, S. Sharma dan H. Malik, 2016, "Learning Vector Quantization Neural Network Based External Fault Diagnosis Model for Three Phase Induction Motor Using Current Signature Analysis," Procedia Computer Science, vol. 93, pp. 1010-1016.

[5] E. Sediyono, Y. Nataliani dan C. M. Rorimpandey, 2009, "Klasifikasi Sidik Jari dengan Menggunakan Wavelet Symlet," Jurnal INFORMATIKA, vol. 5, no. 2, pp. 16-34.

[6] A. Wibowo, Wirawan dan Y. K. Suprapto, 2014, "Verifikasi dan Identifikasi Tandatangan Offline Menggunakan Wavelet dan Learning Vector Quantization," in Seminar Nasional Sains dan Pendidikan Sains IX Fakultas Sains dan Matematika UKSW. 